\title{
ISSQN SOBRE A PRESTAÇÃO DE SERVIÇO NA CONSTRUÇÃO CIVIL
}

\author{
ISSQN: tax on works contract as service
}

\section{Helton Kramer Lustoza}

Mestre em Direito Constitucional pela UNIBRASIL, com estudos na UFPR. Especialista em Direito Tributário. Especialista em Processo Civil. Graduado em Direito pela Universidade Positivo. Procurador do Estado do Paraná.

\section{Resumo}

O presente estudo baseia-se na análise das principais polêmicas que giram em torno da tributação do ISSQN. Passa-se a analisar a questão do critério material e espacial do ISSQN, que por muito tempo foi contraditório, mas que atualmente se encontra pacificado na doutrina e na jurisprudência. Também aborda a polêmica questão da alíquota mínima do artigo 88 da ADCT e a dedução de materiais da base de cálculo do ISSQN.

Palavras-chave: Imposto. Constituição. Incidência. Alíquota. Razoabilidade.

\section{Abstract}

This paper is based on most relevant controversies about ISSQN. If the analyze the question of the criteria material and spatial of the ISSQN, what for a long time was conflicting, but what actually if she meets pacifying on doctrine and on jurisprudence. Also approach the polemic question from aliquota minimum of the product 88 from ADCT and the deduction of materials from base of calculation of the ISSQN.

Keywords: Tax. Constitution. Tax levy. Aliquot. Reasonability.

\section{Sumário}

1. Aspecto material da hipótese de incidência tributária; 2. O aspecto espacial e conflitos de competência; 3 . Ofensa à autonomia municipal: limitação da alíquota mínima do ISSQN; 4. A base de cálculo do ISSQN na construção civil e a repercussão do entendimento do Supremo Tribunal Federal; 5. Notas; Referências 


\section{ASPECTO MATERIAL DA HIPÓTESE DE INCIDÊNCIA TRIBUTÁRIA}

A Constituição Federal de 1988, em seus artigos 153 a 156, define a competência tributária da União, Estados, DF e Municípios, de forma a reconhecer seus limites e condições como pressuposto para legitimidade do sistema. Lembra Roque Antonio Carrazza que ao mesmo tempo em que as normas constitucionais habilitam as pessoas políticas a criarem seus tributos, também impede as demais de alterá-lo. ${ }^{1}$

Frente a isso, é certo que a Carta Constitucional previu várias situações onde a prestação de serviço será tributada por impostos diferentes, tais como serviço de transporte intermunicipal (ICMS), serviço de comunicação (ICMS) e serviços de outras naturezas (ISSQN). Para se identificar o imposto correto, o intérprete deverá realizar o enquadramento do fato concreto perante a hipótese abstratamente prevista pela lei tributária. Sem que se verifique tal enquadramento não se pode afirmar que existe um fato jurídico tributário, conforme entendimento de Paulo de Barros Carvalho:

O objeto sobre o qual converge o nosso interesse é a fenomenologia da incidência da norma tributária em sentido estreito ou regra-matriz de incidência tributária. Nesse caso, diremos que houve a subsunção, quando o fato (fato jurídico tributário constituído pela linguagem prescrita pelo direito positivo) guardar absoluta identidade com o desenho normativo da hipótese (hipótese tributaria). ${ }^{2}$

O arquétipo constitucional do ISSQN está previsto pelo artigo 156 da Carta Magna, através do qual é garantida aos Municípios a competência tributária para instituir imposto sobre "serviços de qualquer natureza, não compreendidos no art. 155, II, definidos em lei complementar". Esse dispositivo constitucional, além de prever a incidência sobre a prestação de serviços, estabeleceu dois pontos de extrema importância para o tema: primeiro, revelando a preocupação entre o conflito do ISSQN e ICMS; outro, delegando à legislação complementar a missão de editar normas gerais sobre este tributo municipal.

Com o advento da Lei Complementar n. ${ }^{\circ}$ 116/2003 surgiu várias polêmicas em relação à incidência tributária, em especial sobre a tributação da construção civil. Esta celeuma tem sido objeto de inúmeras discussões no âmbito doutrinário e jurisprudencial, causando certa insegurança jurídica.

Em linhas gerais, o critério material do ISSQN está previsto no art. $1^{\circ}$ da Lei Complementar 116/2003, o qual define como fato gerador "a prestação de serviços constantes da lista anexa, ainda que esses não se constituam como atividade preponderante do prestador". Nesse sentido, somente é permitido ao Município arrecadar o ISSQN sobre serviços não compreendidos na competência da União e dos Estados, isso levou a entender que a lista de serviços seria taxativa. O entendimento adotado no âmbito do Supremo Tribunal Federal vai ao encontro deste raciocínio, a ponto de definir ser taxativa a lista de serviços, embora admita interpretação ampla e analógica. Significa afirmar que a lista é taxativa, mas em alguns de seus itens, com expressões como "e outros" e "congêneres", é possível uma interpretação ampliativa. ${ }^{3}$

Em decorrência deste entendimento, os serviços não incluídos na lista, prevista na Lei Complementar n. ${ }^{0}$ 116/2003, não estão sujeitos à incidência do ISS por inexistência de competência tributária municipal. A partir disso, tem-se uma definição clara de que o núcleo 
da descrição fática deve estar concretizado na conjugação das terminologias: "prestar + serviços".

Nesta perspectiva, a prestação de serviços de qualquer natureza, para fins de incidência de ISSQN, deve estar compreendida a partir da presença de três pressupostos: efetividade do serviço, habitualidade e finalidade lucrativa. O aspecto material do ISSQN está ligado ao fato de se desenvolver um esforço a fim de cumprir uma obrigação de fazer, sendo importante para a análise da incidência tributária a sua prestação e não o resultado (produto). Isso faz com que se conclua que esta exação municipal não pode incidir sobre o serviço em potencial, mas sim, sua materialidade resultará da efetiva prestação de serviço, conforme leciona o Aires F. Barreto:

o ISS, e bem assim qualquer outro imposto, só pode alcançar o fato concretamente ocorrido no mundo fenomênico, e nunca aquele que está por ocorrer, ainda que a probabilidade dessa ocorrência seja presumível. Relativamente ao ISS, é preciso atentar, ainda, para a circunstância de que se trata de um imposto sobre fatos e não sobre contratos. ${ }^{4}$

A segurança jurídica desta forma de tributação está centrada na exata diferença entre a obrigação de "fazer" e a obrigação de "dar", sendo de fundamental importância para identificar os fatos sujeitos a sua incidência. A professora Maria Helena Diniz contribui de forma magistral para esta distinção, quando traça tais diferenças da seguinte forma:

A prestação, na obrigação de dar, consiste na entrega de um objeto, sem que
se tenha de fazê-lo previamente, e, na de fazer, na realização de um ato ou
confecção de uma coisa, para depois entrega-la ao credor.

Nessa linha de raciocínio, em análise sobre a locação de bens móveis, o Supremo Tribunal Federal definiu se tratava de uma obrigação de dar, afastando a incidência de ISSQN. Tempos depois, a Suprema Corte pacificou esse mesmo entendimento através da Súmula Vinculante n. 31, em que consignou: "é inconstitucional a incidência do Imposto sobre Serviços de Qualquer Natureza (ISS) sobre operações de locação de bens móveis.”

Depreende-se do texto legal, que o aspecto material da hipótese de incidência do ICMS não é a mercadoria em si, mas a sua circulação jurídica, que deve ser entendida como a transferência sucessiva de sua titularidade. É natural que uma empresa que comercializa equipamentos de informática (operação sujeita ao ICMS) também venha a realizar serviços de assistência destes mesmos produtos. Somente com a análise da lista de serviços será possível identificar se esta atividade se enquadra na hipótese de incidência do imposto, independente deste constituir ou não atividade preponderante do prestador.

Contudo, a regra somente valerá se o serviço não for considerado como atividade-meio, com autonomia em relação à obrigação principal. É o que ocorre, por exemplo, com a venda de ar condicionado, cuja comercialização da mercadoria inclui, muitas vezes, a sua instalação. Quando a prestação de serviço for parte integrante da relação jurídica ela será considerada como atividade-meio, o que consequentemente afasta a incidência do tributo municipal.

O conflito entre ISSQN e ICMS fica ainda mais evidente diante da prestação e serviço em que haja a aplicação de bens, materiais e insumos. Essa polêmica teve sua solução estabelecida pela jurisprudência, sendo que o Superior Tribunal de Justiça passou a fazer 
a distinção entre os programas feitos por empresas em grande escala (estaria sujeito ao ICMS) e aqueles softwares elaborados sob encomenda, sendo que neste último caso ficará sujeito ao ISSQN. ${ }^{6}$

Com isso, ficou definido que as atividades constantes da lista, sem ressalva quanto à incidência do ICMS, estão sujeitas somente ao ISS, ainda que na sua prestação se verifique o fornecimento de materiais.

\section{O ASPECTO ESPACIAL E CONFLITOS DE COMPETÊNCIA}

Outro ponto a ser abordado seria a respeito do local de pagamento do ISSQN, o que exigiu o desenvolvimento de critérios claros para o correto entendimento do Município competente, sob pena de cair na armadilha daquele famoso vocábulo jurídico: "quem paga mal, paga duas vezes".

Antes mesmo da atual legislação complementar, o local da prestação do serviço era regulado pelo $D L n .^{\circ} 406 / 68$, que assim estabelecia:

Art. 12. Considera-se local da prestação de serviço:

a) o do estabelecimento prestador ou, na falta de estabelecimento, o do domicílio do prestador;

b) no caso de construção civil, o local onde se efetuar a prestação.

Observe-se que o DL n. ${ }^{\circ}$ 406/68 havia adotado como regra geral de incidência do ISS, o local do estabelecimento do prestador e, na sua falta, o seu domicílio. A exceção à regra geral ocorreria no caso dos serviços de construção civil, incidindo no local da prestação do serviço (local da obra). Naquele momento, a jurisprudência tinha pacificado o entendimento no sentido de que o Município competente para cobrança do imposto, em qualquer situação, é aquele em cujo território em se realizasse o fato gerador. Este entendimento foi adotado através da $1^{\text {a }}$ Seção no julgado dos Embargos em Recurso Especial n. ${ }^{0}$ 130.792/CE. ${ }^{7}$

Apesar do DL 406/68 ter previsto expressamente que o serviço de construção civil seria o único caso em que se deveria adotar a regra do critério do local da ocorrência do fato gerador, a corrente jurisprudencial e doutrinária majoritária caminhava em sentido contrário, adotando a regra para todas as situações. Tanto é assim que na década de 80 , Geraldo Ataliba e Aires F. Barreto defenderam a inconstitucionalidade da alínea "a" do art. 12 do DL n. ${ }^{\circ}$ $406 / 68$, frente a ordem constitucional. Estes doutrinadores manifestaram-se no sentido de que "o aspecto espacial da hipótese de incidência é implicitamente extraível do Texto Constitucional. Se o arquétipo é a prestação de serviço, o aspecto espacial só pode ser reduzido ao local onde se efetua a prestação."

Embora esta fosse uma posição já consolidada na jurisprudência e doutrina, a Lei Complementar n. ${ }^{\circ}$ 116/2003 manteve a mesma regra legislativa do local do estabelecimento como competente para arrecadar o ISSQN, acirrando ainda mais a polêmica do assunto. $\mathrm{O}$ art. $3^{\circ}$ desta legislação complementar definiu o aspecto espacial, determinando que "o serviço considera-se prestado e o imposto devido no local do estabelecimento prestador ou, na falta do estabelecimento, no local do domicílio do prestador, exceto nas hipóteses previstas nos incisos I a XXII, quando o imposto será devido no local." 
Assim, após muita polêmica jurisprudencial, o Superior Tribunal de Justiça voltou a analisar esta questão, culminando na modificação do entendimento que vinha seguindo, para acatar a regra entabulada na LC 116/2003:

\begin{abstract}
De acordo com os artigos $3^{\circ}$ e $4^{\circ}$ da Lei Complementar $n^{\circ} 116 / 03$, conclui-se que a municipalidade competente para realizar a cobrança do ISS é a do local do estabelecimento prestador dos serviços, considerando-se como tal a localidade em que há uma unidade econômica ou profissional, isto é, onde a atividade é desenvolvida, independentemente de sua denominação. (REsp 1195844/DF Ministro Relator Mauro Campbell Marques - DJ 15/03/2011).
\end{abstract}

Esta decisão estabelece um novo panorama para esta situação, passando a uniformizar o entendimento acerca da aplicação da regra de local competente para arrecadar o ISSQN. Pode-se afirmar que esta situação ficou mais tranquila quando a primeira seção do Superior Tribunal de Justiça julgou o Recurso Especial n. ${ }^{\circ} 1.117 .121 / \mathrm{SP}$, reafirmando o entendimento segundo o qual, na ocorrência do fato gerador sob a égide da LC 116/2003, à exceção de serviços expressamente previstos nos incisos I a XXII do art. $3^{\circ}$, o ISSQN é devido ao Município do local da sede do prestador de serviço.

Portanto, diante deste novo cenário, a jurisprudencial atual orienta que será competente para arrecadar o ISSQN o Município onde se localiza o estabelecimento (origem da prestação do serviço), salvo as exceções previstas nos incisos I a XXII do art. $3^{\circ}$ da LC 116/2003, dentre elas a construção civil.

\title{
3. OFENSA À AUTONOMIA MUNICIPAL: LIMITAÇÃO DA ALÍQUOTA MÍNIMA DO ISSQN
}

Superada a polêmica acerca do aspecto espacial, outro ponto delicado do tema é a respeito da limitação de alíquotas mínimas de ISSQN feitas pelo art. 88 da ADCT.

Primeiramente, cabe lembrar que a Carta Constitucional, no seu art. 156, §3. ${ }^{\circ}$, I, estabeleceu que caberá a lei complementar fixar as alíquotas máximas e mínimas do ISSQN, sendo que no primeiro caso tem-se a previsão de 5\% (LC 116/03, art. $8^{\circ}$, II) e no segundo caso não houve previsão expressa na legislação complementar.

A polêmica está centrada no fato do constituinte derivado ter alterado o art. 88 do ADCT, a fim de incluir a vedação aos Municípios, no que tange ao tributo ISSQN, estabelecendo alíquotas mínimas inferiores a $2 \%$, bem como concedendo benefícios e isenções até que a Lei Complementar venha regulamentar esta situação:

\footnotetext{
Art. 88. Enquanto lei complementar não disciplinar o disposto nos incisos I e III do $\S 3^{\circ}$ do art. 156 da Constituição Federal, o imposto a que se refere o inciso III do caput do mesmo artigo:

I - terá alíquota mínima de dois por cento, exceto para os serviços a que se referem os itens 32, 33 e 34 da Lista de Serviços anexa ao Decreto-Lei n 406 , de 31 de dezembro de 1968;

II - não será objeto de concessão de isenções, incentivos e benefícios fiscais, que resulte, direta ou indiretamente, na redução da alíquota mínima estabelecida no inciso I.
}

Este dispositivo constitucional é expresso em definir que na ausência de Lei Complementar regulamentadora, os Municípios não poderiam conceder isenções, salvos casos especiais expressamente definidos. Posteriormente, a Lei Complementar n. 116/2003 foi 
editada para definir normas gerais do ISSQN, sendo omissa, contudo, quanto aos benefícios fiscais.

A determinação de uma alíquota mínima trata-se de uma inovação feita pelo legislador constituinte derivado com a clara intenção de evitar a prática da denominada guerra fiscal.

Primeiramente, pode-se identificar uma inconstitucionalidade do artigo 88 do ADCT, inserido pela Emenda $n^{\circ} 37 / 2002$, por afrontar a autonomia municipal e, por decorrência, o princípio federativo. Esta inconstitucionalidade é flagrante, na medida em que interfere e engessa o exercício da competência tributária dos Municípios. Esta interferência federal na competência tributária municipal não é permitida pela Constituição Federal, nem mesmo por meio de uma emenda constitucional, uma vez que o princípio federativo constitui uma cláusula pétrea, de acordo com o artigo $60, \S 4^{\circ}$, inciso I.

Nestes termos, Aires F. Barreto entendeu ser inconstitucional a Emenda n. ${ }^{\circ}$ 37/2002, esclarecendo que "parece, a todos os títulos, que se tem aí afronta ao magno princípio da autonomia municipal. Quem é competente para instituir também o é para isentar, reduzir, incentivar. ${ }^{9}$ Também existem outros posicionamentos na doutrina, como Kiyoshi Harada, que defendem a inconstitucionalidade da fixação de uma alíquota mínima do ISSQN por meio de emenda constitucional. ${ }^{10}$

Entretanto, não há um posicionamento claro da jurisprudência pátria, apenas, as raras decisões encontradas, definem ser constitucional as limitações do art. 88 da ADCT e, portanto, aplicáveis. ${ }^{11}$ Além disso, o princípio da presunção de constitucionalidade nos impõe o entendimento de que até futura declaração expressa da contradição da atual redação do art. 88 para com a ordem constitucional, sua normatividade deve ser respeitada.

Em contrapartida, sua interpretação deve guardar simetria com os reais objetivos da ordem tributária constitucional, de forma que a norma em comento seja aplicada inteligentemente. Ao momento da edição de uma norma jurídica há uma vontade implícita do legislador, mas também há um objetivo ou a finalidade precípua de solucionar celeumas jurídicas, o que deve ser levado em conta no momento da interpretação/aplicação da norma.

Por isso, ultrapassada a questão da validade "duvidosa" do artigo 88, do ADCT, o dispositivo deve receber uma interpretação teleológica, a fim de se identificar a verdadeira finalidade da norma constitucional. Além disso, o dispositivo deve ser cotejado com todo o sistema constitucional (interpretação sistemática), evitando uma apreciação isolada e literal do seu texto. É nesse sentido que J. J. Gomes Canotilho comenta que "o intérprete deva sempre considerar as normas constitucionais, não como normas isoladas e dispersas, mas sim como preceitos integrados num sistema interno e unitário de normas e princípios." ${ }^{12} \mathrm{O}$ que leva ao entendimento de que toda norma constitucional precisa estar interligada à finalidade determinada, a qual deve ser identificada no momento da interpretação.

Está claro que o artigo 88, da ADCT, não estabelece um impedimento de incentivos fiscais à toa, há uma intenção clara de se evitar uma disputa fiscal (cunho arrecadatório). Em outras palavras, sem dificuldade alguma é possível identificar que o art. 88 visa evitar a guerra fiscal entre os municípios, proibindo a utilização de incentivos fiscais de forma indis- 
criminada, prejudicando, muitas vezes, o equilíbrio fiscal da própria municipalidade.

No caso de ser identificada esta finalidade da norma constitucional, a fixação da alíquota mínima de $2 \%$ para o ISSQN não se trata de uma norma voltada a limitações constitucionais ao poder de tributar, nem para o estabelecimento de normas gerais do tributo, mas sim, tem como único e verdadeiro intuito evitar guerras fiscais entre os Municípios. Porquanto, sua aplicação deve ocorrer a fim de tal finalidade específica, sendo que diante da ausência desta indesejada disputa fiscal entre municípios, o dispositivo perde razão de ser.

Reflexão: se não é esse o raciocínio, então se indaga o porquê do inciso I, do artigo 88 excepcionar a aplicação da limitação de alíquota para os serviços de construção civil (itens 32, 33 e 34 da antiga Lista de Serviços)? Por uma simples razão, o aspecto espacial do ISSQN da prestação de serviços relacionados à construção civil ocorreria no local aonde irá se efetuar a prestação, ou seja, não havia um ambiente propício nem passível de sofrer guerra fiscal. Este raciocínio, encadeado por uma interpretação teleológica, acaba impondo novas reflexões acerca do atual alcance do artigo 88 da ADCT, uma vez que outros serviços passaram a ter como elemento espacial o local da prestação do serviço, e não mais o local onde está situado o estabelecimento da empresa, como se depreende do artigo $3^{\circ}$, incisos II a XXII.

Nestes termos, a lição de Luis Roberto Barroso se aplica perfeitamente a situação, quando ele afirma que: "as normas devem ser aplicadas atendendo, fundamentalmente, ao seu espírito e à sua finalidade. [...] procura revelar o fim da norma, o valor ou bem jurídico visado pelo ordenamento com a edição de dado preceito." ${ }^{13}$ Com efeito, o art. $3^{\circ}$ da LC n. ${ }^{\circ}$ 116/03 é autossuficiente para eliminar a disputa fiscal entre os Municípios quanto aos serviços ali discriminados, prescindindo, portanto, a limitação de alíquota prevista no art. 88 da ADCT. Neste ponto, entende-se que a limitação de alíquota mínima prevista deve ser aplicada somente em casos de nítida possibilidade de guerra fiscal. Por outro lado, se o benefício fiscal não implicar prejuízo aos outros municípios, não há de se cogitar em uma guerra fiscal.

Um ponto que pode gerar polêmica, no âmbito municipal, diz respeito a previsão na Lei n. ${ }^{0}$ 12305/2010 sobre a Política Nacional de Resíduos Sólidos. No art. 44, desta legislação, há a previsão de que "a União, os Estados, o Distrito Federal e os Municípios, no âmbito de suas competências, poderão instituir normas com o objetivo de conceder incentivos fiscais, financeiros ou creditícios, respeitadas as limitações da Lei Complementar n. ${ }^{\circ} 101$, de 4 de maio de 2000 (Lei de Responsabilidade Fiscal)". A legislação aprovada pela União, de cunho nacional, tenta incentivar, por meio de benefícios fiscais, condutas da sociedade.

Portanto, é possível identificar benefícios fiscais concedidos com fins sociais, o que já poderia, de antemão, verificar a ausência de qualquer disputa fiscal que ensejasse a aplicação do art. 88 da ADCT. Além disso, poder-se-ia visualizar certos incentivos finalísticos, sob condições específicas, ligado aos objetivos constitucionais do art. $3^{\circ}$ da Constituição Federal de 1988. 


\section{A BASE DE CÁLCULO DO ISSQN NA CONSTRUÇÃO CIVIL E A REPERCUSSÃO DO ENTENDIMENTO DO SUPREMO TRIBUNAL FEDERAL}

A base de cálculo pode ser compreendia como a grandeza econômica que advém dos fatos jurídicos sujeitos aos tributos. Contudo, a grandeza efetiva dos acontecimentos e os fatos não são mensuráveis em sua integralidade, o que mostra a necessidade de delimitar a base de cálculo, compatível com sua natureza. Assim, afirma Paulo de Barros Carvalho que a função da base de cálculo, pela teoria geral do direito tributário, é confirmar o verdadeiro critério material da hipótese tributária, de modo a identificar três funções:

\footnotetext{
a) função mensuradora, pois mede as proporções reais do fato; b) função objetiva, porque compõe a específica determinação da dívida e; c) função comparativa, porquanto, posta em comparação com o critério material da hipótese, é capaz de confirmá-lo, infirmá-lo ou afirmar aquilo que consta no texto da lei, de modo obscuro. ${ }^{14}$
}

No caso do ISSQN a base de cálculo deverá se amoldar ao preço do serviço, que será a contraprestação estabelecida em troca de uma obrigação de fazer. O que muitas vezes era confundido com ingressos financeiros, isto é, nem todo ingresso de valores oriundo do negócio jurídico se enquadrará na base de cálculo deste tributo municipal.

Existem alguns valores que ingressam no caixa do prestador do serviço que, embora se originem do mesmo negócio jurídico, não fazem parte da hipótese de incidência do ISSQN. A sua base de cálculo, como todo o tributo, deve estar delimitada pelo princípio da legalidade, na medida em que precisa estar definido por lei municipal (art. 97 CTN), sendo que esta previsão deve estar em consonância com as normas gerais do tributo (art. 146, III $\mathrm{CF} / 88)$.

A previsão legal da base de cálculo do ISSQN está no art. $7^{\circ}$ da Lei Complementar $\mathrm{n}$. 116/03, onde estabelece o critério do preço do serviço. Em serviços simples não há maiores dificuldades da sua identificação, como por exemplo, após a prestação de serviços de representação comercial, o tributo incide sobre o preço acordado. Entretanto, a dificuldade se concentra nos casos em que os serviços são acompanhados de utilização de materiais e instrumentos, ainda mais, diante do fato de que nem todo ingresso pode ser considerado receita direta da prestação de serviço. É o que acontece com o serviço de trabalho temporário, onde o ISS incidirá somente sobre a taxa de administração, exceto se o empregado for contratado pela empresa intermediadora. Neste tipo de serviço o Superior Tribunal de Justiça compreendeu ser correta a tese de que deveria haver o abatimento do valor referente à mão-de-obra. ${ }^{15}$

A doutrina costuma diferenciar o preço da prestação (base de cálculo do ISSQN) com o preço do serviço, sendo que o conceito deste último engloba, além do valor da prestação, valores gastos com a prestação. ${ }^{16}$ Essa diferenciação é de suma importância em serviços em que haja a aplicação de materiais e instrumentos, na medida em que há uma dificuldade maior para se identificar a real base de cálculo do tributo. No que se refere à incidência tributária da prestação de serviços de construção civil possui expressa previsão na lista de serviços da Lei Complementar 116/2003, conforme item 7.02, interferindo na delimitação da base de cálculo do tributo: 
7.02 - Execução, por administração, empreitada ou subempreitada, de obras de construção civil, hidráulica ou elétrica e de outras obras semelhantes, inclusive sondagem, perfuração de poços, escavação, drenagem e irrigação, terraplanagem, pavimentação, concretagem e a instalação e montagem de produtos, peças e equipamentos (exceto o fornecimento de mercadorias produzidas pelo prestador de serviços fora do local da prestação dos serviços, que fica sujeito ao ICMS).

Observe-se que o dispositivo legal acima citado é expresso em afirmar que haverá a incidência de ISSQN sobre o valor integral da prestação do serviço, ressalvando o fornecimento de mercadorias produzidas pelo prestador do serviço fora do local da obra. Para isso, é necessário realizar uma interpretação conjunta dos dispositivos da LC 116/2003 para se ter uma conclusão lógica e coerente. Seria temerário obter sínteses parciais, com base em dispositivos legais isolados, o que leva a necessidade de averiguar alguns desdobramentos desta discussão.

Durante alguns anos o Superior Tribunal de Justiça tinha o posicionamento sacramento no sentido de que na prestação de serviço de construção civil ocorria a incidência do ISSQN sobre o valor global do serviço, sem autorização de dedução de materiais, exceto quanto a previsão da parte final do item $7.02 .{ }^{17}$ Isto porque na construção civil existe uma obrigação de uma atividade fim, qual seja: a prestação de serviço direcionado a entrega de uma obra. Tal entendimento leva a conclusão de que, o conceito de prestação de serviço, independe se o prestador utilizou ou aplicou materiais para consecução de seu objetivo. Em outras palavras, não desnatura o contrato, se o dentista usou anestésico e se o engenheiro teve que adquirir uma trena.

A incorporação de bens na obra fez com que tais materiais perdessem suas qualidades de origem, transformando-se em elementos da construção, isto é, o tomador do serviço não contratou o recebimento destes materiais, mas simplesmente eles foram transformados em insumos e foram adicionados à obra.

Cabe ainda mencionar a respeito da súmula n. ${ }^{\circ} 167$, do Superior Tribunal de Justiça, a qual prevê o entendimento de que o fornecimento de concreto para construção civil, preparado no trajeto até a obra, sujeita-se somente ao ISS. Neste caso, conforme explica Andrei Pitten Velloso, "os materiais empregados na prestação de serviços são, com frequência, elementos imprescindíveis à sua conclusão, não se qualificando necessariamente como mercadorias, por não serem bens destinados ao comércio."18

Nesta perspectiva, a hipótese de incidência do ICMS como sendo a operação relativa à circulação em si mesma considerada, revela-se apenas quando haja movimentos de mercadorias que sejam imputáveis a negócios jurídicos translativos da sua titularidade. ${ }^{19}$ No que tange as obras de construção civil, é importante esclarecer que a conclusão dos contratos firmados por empreitada não há a transferência, à contratante, de parte do empreendimento executado ou dos materiais individualmente empregados, mas sim, a entrega da obra como um todo. Tanto é assim que, nos termos do art. 610 do Código Civil, o contrato de empreitada pode advir somente da contribuição do trabalho do empreiteiro ou, também, com o emprego de materiais. Em ambas as situações, o contrato de empreitada se caracterizaria como obrigação de fazer, sendo que o material empregado se transformou em insumo da obra. 
De forma contrária a este posicionamento, o Supremo Tribunal Federal, através de um voto monocrático da ministra Ellen Gracie no Recurso Extraordinário n. 603497, julgou pela possibilidade da dedução de materiais da base de cálculo da prestação de serviços da construção civil da seguinte forma:

\begin{abstract}
A hipótese dos autos versa sobre a constitucionalidade da incidência do ISS sobre materiais empregados na construção civil. O acórdão assim decidiu: "TRIBUTÁRIO - ISS - CONSTRUÇÃO CIVIL - BASE DE CÁLCULO - MATERIAL EMPREGADO - DEDUÇÃO - IMPOSSIBILIDADE. A jurisprudência desta Corte pacificou o entendimento de que a base de cálculo do ISS é o preço total do serviço, de maneira que, na hipótese de construção civil, não pode haver a subtração do material empregado para efeito de definição da base de cálculo. Precedentes de Corte. Agravo regimental improvido." 2. Este Tribunal, no julgamento do RE 603.497, de minha relatoria, reconheceu a existência da repercussão geral da matéria para que os efeitos do art. 543-B do CPC possam ser aplicados. Esta Corte firmou o entendimento no sentido da possibilidade da dedução da base de cálculo do ISS dos materiais empregados na construção civil. O acórdão recorrido divergiu desse entendimento. 3. Ante o exposto, com fundamento no art. 557, $\S 1^{\circ}-\mathrm{A}$, do CPC, dou provimento ao recurso extraordinário. (RE 603497, Relator(a): Min. ELLEN GRACIE, julgado em 18/08/2010, publicado em DJe-172 DIVULG 15/09/2010 PUBLIC 16/09/2010).
\end{abstract}

Em outra situação, o Supremo Tribunal Federal voltou a se pronunciar sobre o tema, definindo a recepção e aplicação do art. $9^{\circ}$ do DL n. 406/68.

\begin{abstract}
EMENTA: AGRAVO REGIMENTAL EM RECURSO EXTRAORDINÁRIO. ISS. CONSTRUÇÃO CIVIL. BASE DE CÁLCULO. ABATIMENTO DOS MATERIAIS E SUBEMPREITADAS. POSSIBILIDADE. 1. A jurisprudência do Supremo Tribunal Federal é firme no sentido de que o art. $9^{\circ}$ do Decreto-Lei 406/1968 foi recepcionado pela Constituição Federal de 1988. Pelo que é possível a dedução da base de cálculo do ISS dos valores dos materiais utilizados em construção civil e das subempreitadas. 2. Agravo regimental desprovido. (RE $599582 \mathrm{AgR}$, Relator(a): Min. AYRES BRITTO, Segunda Turma, julgado em 29/03/2011, DJe-123 DIVULG 28-06-2011 PUBLIC 29-06-2011 EMENT VOL-02553-02 PP-00233).
\end{abstract}

Após esta manifestação pela Suprema Corte, o Superior Tribunal de Justiça alterou seu entendimento relativo à definição da base de cálculo do ISSQN na construção civil, passando a aceitar a possibilidade da dedução dos materiais. Na mesma situação jurídica, este Tribunal afastou a incidência do ISS sobre as subempreitadas e definiu que os materiais que poderiam ser deduzidos seriam aqueles empregados na obra:

PROCESSUAL CIVIL E TRIBUTÁRIO. AGRAVO REGIMENTAL NO AGRAVO REGIMENTAL NO AGRAVO DE INSTRUMENTO. MANDADO DE SEGURANÇA. ISS. CONSTRUÇÃO CIVIL. BASE DE CÁLCULO. ABATIMENTO DOS MATERIAIS EMPREGADOS E DAS SUBEMPREITADAS. POSSIBILIDADE. ENTENDIMENTO DO SUPREMO TRIBUNAL FEDERAL. 1. O STF, por ocasião do julgamento do RE 603.497/MG, Rel. Min. Ellen Gracie, DJ de 16/9/2010, reconheceu a repercussão geral sobre o tema, consoante regra do art. 543-B, do CPC, e firmou entendimento no sentido da possibilidade da dedução da base de cálculo do ISS dos materiais empregados na construção civil. 2. No mesmo sentido, o eminente Ministro Carlos Ayres Britto, no Agravo Regimental no RE 599.582/RJ, DJ de 29/6/2011, assentou: "A jurisprudência do Supremo Tribunal Federal é firme no sentido de que o art. $9^{\circ}$ do Decreto-Lei 406/1968 foi recepcionado pela Constituição Federal de 1988. Pelo que é possível a dedução da base de cálculo do ISS dos valores dos materiais utilizados em construção civil e das subempreitadas." (AgRg no AgRg no Al n 1.410.608, $1^{\text {a }}$ Turma, relator Ministro Benedito Gonçalves, julgado em 18/10/2011, publicado no DJe de 21/10/2011).

Tanto a legislação antiga (DL 605/68), quanto a nova (LC 116/2003), permitem que a formação do preço do serviço seja formada através da identificação do valor integral com a subtração do valor dos materiais fornecidos pelo prestador do serviço (art. $7^{\circ}, \S 2^{\circ}$, I, 
da Lei Complementar $n^{\circ}$ 116/03). Note-se que a fundamentação da Suprema Corte é da possibilidade da dedução dos materiais na construção civil, mas resta responder a seguinte indagação: que tipos de materiais podem ser deduzidos da base de cálculo? Há possibilidade de deduzir materiais adquiridos de terceiros? A dedução está restrita aos materiais incorporados à obra ou alcança aqueles utilizados de forma indireta?

Isso mostra que a presente pesquisa tem três campos investigativos:

a) materiais produzidos pelo prestador do serviço fora do canteiro da obra

b) materiais adquiridos de terceiro pelo prestador do serviço

c) diferença entre materiais empregados na obra e materiais utilizados de forma indireta pelo prestador do serviço na obra

$\mathrm{Na}$ leitura de Aires F. Barreto, o fato de a lei complementar não permitir a inclusão dos materiais equivale a dizer que materiais não integram a base de cálculo do ISSQN, isto em razão da não cumulatividade do imposto. Entende, este autor, que o veto ocorrido no inciso II do $\S 2^{\circ}$ da LC 116/2003 é inconstitucional, pois a não dedução das subempreitadas afrontaria a própria estrutura constitucional do imposto. ${ }^{20}$ Diante disso, a pesquisa irá partir de algumas premissas: a primeira acerca da possibilidade de dedução dos valores de subempreitadas já tributadas pelo ISSQN (conforme prevista no art. $9^{\circ}$ do DL 406/68); outra, é da possibilidade de dedução de materiais, ficando sujeito a indagações somente a definição de quais os materiais que poderiam ser deduzidos.

Uma interpretação literal levaria a conclusão de que a única exceção cabível prevista na lista de serviços ocorre quando o prestador do serviço alia essa atividade à de industrial ou comerciante, alienando mercadorias. Neste caso, teria, ao menos em tese, duas obrigações que se cumprem: "dar" e "fazer", isto é, junto com a prestação do serviço existiram mercadorias produzidas por ele e vendidas ao tomador do serviço. ${ }^{21}$ Por outro lado, existe a corrente doutrinária que defende que não poderia haver limitação da dedução dos materiais fornecidos pelo prestador, haja vista a redação do art. $7^{\circ}$ da LC n. ${ }^{\circ}$ 116/2007 utilizar o termo "material fornecido" e não o termo "produzido".

Até que venha uma decisão definitiva e expressa da Suprema Corte, resta a Fazenda Pública Municipal e aos contribuintes interpretarem os preceitos e delimitações essenciais para alcançar uma decisão coerente. Assim, apesar da fundamentação da sentença não ser alcançada pela coisa julgada, é parte muito importante para permitir a perfeita e correta interpretação do entendimento judicial. Neste mesmo sentido salienta Humberto Teodoro Júnior que "deve-se partir do princípio básico de que não é pela simples leitura de seu dispositivo e de sentido literal que se consegue extrair seu sentido e alcance."22 Desta forma, é a partir do cotejo entre o dispositivo e a fundamentação do julgado que se torna possível concluir acerca do alcance e aplicação da decisão judicial. Por isso, se mostra importante, para não dizer indispensável, a leitura e entendimento dos fundamentos das decisões dos Tribunais superiores para sua interpretação.

Através de uma interpretação razoável desta situação, não parece coerente prevalecer o entendimento de que o Supremo Tribunal Federal simplesmente permitiu a dedução 
de todo e qualquer material da base de cálculo do ISSQN em casos de construção civil, até porque a lei assim não permitiu. Pelo contrário, a fundamentação das decisões da Suprema Corte, consideraram que a dedução é possível, mas deve se limitar somente aos materiais empregados diretamente na obra. Com isso, fica claro que a legislação tributária juntamente com a jurisprudência dominante, pretendem excluir da base de cálculo, corresponde ao valor total do serviço de construção civil prestado, tão-somente, os valores advindos de materiais que tenham origem de uma venda mercantil (sujeita a tributação do ICMS) e desde que sejam empregados (incorporadores definitivamente) na obra.

A terminologia "materiais fornecidos", previsto no art. $7^{\circ}$ da LC n. ${ }^{0} 116 / 2003$ não chega ao ponto de englobar materiais utilizados indiretamente na obra. Por exemplo, seria equivocada a permissão de abatimento de valores como carrinhos de mão, capacetes, tapumes, guindastes, papeis higiênicos e outros materiais que poderiam ser utilizados em várias obras de uma forma auxiliar. Por isso, acredita-se que o abatimento de valores da base de cálculo deve ser realizado com cautela e atenção, pois deverá haver a efetiva comprovação de que os materiais foram devidamente aplicados na obra, independente de serem adquiridos ou produzidos pelo prestador.

A título de exemplo, pode-se apontar a legislação do Município de São Paulo, onde o art. 14 da Lei n. 13701/2003, permite o abatimento de materiais na prestação de serviços de construção civil, desde que sejam incorporados à obra:

\footnotetext{
Art. 14. A base de cálculo do Imposto é o preço do serviço, como tal considerada a receita bruta a ele correspondente, sem nenhuma dedução, excetuados os descontos ou abatimentos concedidos independentemente de qualquer condição.

$\S 7^{\circ}$ Quando forem prestados os serviços descritos nos subitens 7.02, 7.04, $7.05,7.15$ e 7.19 da lista do "caput" do artigo $1^{\circ}$, o Imposto será calculado sobre o preço do serviço deduzido das parcelas correspondentes:

I - ao valor dos materiais incorporados ao imóvel, fornecidos pelo prestador de serviços.
}

A terminologia utilizada pela legislação paulista parece ser adequada à situação, na medida em que respeita o direito de abatimento dos materiais, bem como conserva a cautela da fiscalização municipal em delimitar a base de cálculo conforme os ditames constitucionais. $E$ também respeita a possibilidade de dedução de materiais fornecidos pelo prestador, exigindo a comprovação da incorporação destes na obra.

Esse também foi o entendimento encontrado no Conselho de Contribuintes paulista, abalizando o que vem sendo exigido pela Lei n. 13701/2003: 
os conseqüentes comprovantes de recolhimento de ISS. (CC-SP - PA n ${ }^{\circ} 2006-$ 0.0.31.593-9 - Conselheiro Relator: Adelmo da Silva Emerenciano - Câmara Julgadora: $2^{\text {a }}$ Câmara - 27/11/2006).

A dedução dos materiais é um direito inafastável do contribuinte, em homenagem ao princípio da não bitributação, mas deve ser feito com coerência e de forma restritiva, em consonância com a legislação pertinente e ao art. 111 do Código Tributário Nacional. Isso leva a síntese de que a permissão de subtrair, da base de cálculo do ISSQN, o montante referente a todo e qualquer material utilizado na construção civil fere o princípio da razoabilidade. Isso leva a trabalhar com o entendimento de que a dedução não está restrita apenas aos materiais produzidos pelo prestador, mas não inovou legislativamente a ponto de permitir uma dedução de forma absoluta de todos os materiais adquiridos pelo prestador do serviço.

Uma ligação entre o art. $7^{\circ}$ da LC 116/03 e o art. $9^{\circ}$ do DL 406/68 permite que haja uma legitimidade na dedução da base de cálculo de materiais fornecidos (não necessariamente produzidos) pelo prestador, mas é necessário que haja um critério para a realização desta operação. No entanto, o razoável seria permitir somente os materiais empregados definitivamente como insumo na obra.

Acredita-se, ainda, que há um percurso para que a jurisprudência venha a delimitar definitivamente este assunto, tendo em vista o fato de várias turmas e câmaras dos Tribunais Regionais apresentarem divergência quanto ao tema. Há um progresso significativo da jurisprudência após o posicionamento do Supremo Tribunal Federal e a retratação do Superior Tribunal de Justiça. Percebe-se que alguns Tribunais Regionais já revisaram sua jurisprudência, como por exemplo, algumas turmas do Tribunal de Justiça de São Paulo, ${ }^{23}$ Rio de Janeiro ${ }^{24}$ e Paraná. ${ }^{25}$

Contudo, é possível constatar que ainda existem decisões que não permitem qualquer dedução de materiais da base de cálculo na construção civil, o que vem a desrespeitar não somente o posicionamento dos Tribunais superiores, mas também a própria lógica do tributo.

Portanto, tem-se como tendência o amadurecimento jurisprudencial sobre os temas elencados no presente artigo. O que se espera é a seriedade da parte fiscalizatória e do Judiciário, para que o contribuinte receba uma forma de tributação justa e coerente com os primados constitucionais.

\section{NOTAS}

1. CARRAZZA, Roque Antonio. A tributação na Constituição, o princípio da autonomia municipal e o imposto sobre serviços de qualquer natureza (ISS). Questões conexas. In: SANTI, Eurico Marcos Diniz de. Curso de Direito Tributário e Finanças Públicas. São Paulo: Saraiva, 2008, p. 786.

2. CARVALHO, Paulo de Barros. Curso de Direito Tributário. 17. ed. São Paulo: Saraiva, 2005, p. 250.

3. CONSTITUCIONAL. TRIBUTÁRIO. ISS. LEI COMPLEMENTAR: LISTA DE SERVIÇOS: CARÁTER TAXATIVO. LEI COMPLEMENTAR 56, DE 1987: SERVIÇOS EXECUTADOS POR INSTITUIÇÕES AUTORIZADAS A FUNCIONAR PELO BANCO CENTRAL: EXCLUSÃO. I. - É taxativa, ou limitativa, e não simplesmente exemplificativa, a lista de serviços anexa à lei complementar, embora comportem interpretação ampla os seus tópicos. Cuida-se, no caso, da lista anexa à Lei Complementar 56/87. II. - Precedentes do Supremo Tribunal Federal. III. - Ilegitimidade da exigência do ISS sobre serviços expressamente 
excluídos da lista anexa à Lei Complementar 56/87. (RE 361.829/RJ, relator ministro Carlos Velloso, DJ de 24/02/06, p. 51).

4. BARRETO, Aires F. Curso de Direito Tributário Municipal. São Paulo: Saraiva, 2009, p. 322.

5. DINIZ, Maria Helena. Curso de direito civil brasileiro. v. 2. São Paulo: Saraiva, 2002, p. 100.

6. TRIBUTÁRIO - PROGRAMAS DE COMPUTADOR - DL 406/68 - INCIDÊNCIA DO ISS OU DO ICMS. 1. Esta Corte e o STF posicionaram-se quanto às fitas de vídeo e aos programas de computadores, diante dos itens 22 e 24 da Lista de Serviços. 2. Os programas de computador desenvolvidos para clientes, de forma personalizada, geram incidência de tributo do ISS. 3. Diferentemente, se o programa é criado e vendido de forma impessoal para clientes que os compra como uma mercadoria qualquer, esta venda é gravada com o ICMS. 4. Hipótese em que a empresa fabrica programas específicos para clientes. 5. Recurso improvido (REsp 216.967/SP, $2^{\text {a }}$ Turma do Superior Tribunal de Justiça, relatora ministra Eliana Calmon, DJ de 22/04/01, p. 185).

7. EMBARGOS DE DIVERGÊNCIA. ISS. COMPETÊNCIA. LOCAL DA PRESTAÇÃO DE SERVIÇO. PRECEDENTES. I - Para fins de incidência do ISS - Imposto Sobre Serviços -, importa o local onde foi concretizado o fato gerador, como critério de fixação de competência do Município arrecadador e exigibilidade do crédito tributário, ainda que se releve o teor do art. 12, alínea "a" do Decreto-Lei n. ${ }^{\circ}$ 406/68. II - Embargos rejeitados. (EREsp 130.792/CE, $1^{\text {a }}$ Seção do Superior Tribunal de Justiça, relatora ministra Nancy Andrighi, DJ de 12/06/00, p. 66).

8. ATALIBA, Geraldo; BARRETO, Aires F. ISS - Construção civil - Pseudo-serviço e prestação de serviço - Estabelecimento prestador - Local da prestação. In: Revista de Direito Tributário, n 40 , abril/ junho, 1987, p. 93/94.

9. BARRETO, Aires F. O ISS na Constituição e na Lei. São Paulo: Dialética, 2003, p. 345.

10. Cf. HARADA, Kiyoshi. Direito Financeiro e Tributário. São Paulo: Atlas, 2004, p. 426/427.

11. Incidente de inconstitucionalidade Acórdão que suscitou o incidente como preliminar de conhecimento da questão de mérito, reportando-se à argumentação tecida na sentença recorrida Argumentação suficiente para conhecimento do incidente Arguição de nulidade do acórdão rejeitada Incidente conhecido Lei Municipal n" 3 020/04, art l", do Município de Poá, que prorrogou a alíquota mínima do ISSQN cm 0,25\% pelo prazo de dez anos Norma que contrariou o disposto no art 88, I c II, do Ato das Disposições Transitórias da Constituição Federal, acrescentado pela EC n" 37, de 12 de junho de 2002, que estabeleceu alíquota mínima de $2 \%$ e inadmitiu isenções, incentivos e benefícios fiscais que resultasse na redução da alíquota mínima estabelecida para o ISSQN. Arguição conhecida, declarada incidentalmente a inconstitucionalidade do art. I"da Lei Mun 3.020/04, do Município de Poá (TJSP - Incidente de Inconstitucionalidade n`994.09.222.877-8 - Rel. Joisé Santana - Julg. 24/02/2010).

12. CANOTILHO, José Joaquim Gomes. Direito constitucional. Lisboa: Almedina, 2010, p. 233.

13. BARROSO, Luís Roberto. Interpretação e Aplicação da Constituição. São Paulo: Saraiva, 2004. p. 138

14. CARVALHO, Paulo de Barros. Curso de Direito Tributário..., p. 405.

15. "As empresas agenciadoras de mão-de-obra temporária devem recolher ISS tão somente sobre o preço da taxa de comissão, quando trata-se de mera intermediação. Precedentes. 3. Agravo regimental não provido"(AgRg no AREsp 25.600/DF, Rel. Ministro CASTRO MEIRA, SEGUNDA TURMA, julgado em 12/06/2012).

16. Cf. BAPTISTA, Marcelo Caron. A norma tributária do Imposto sobre Serviços - ISS ênfase no consequente normativo. In. SANTI, Eurico Diniz de. Curso de Direito Tributário e Finanças Públicas. São Paulo: Saraiva, 2008, p. 1048. 
17. $A$ tese de que não apenas os materiais produzidos pelo próprio prestador, mas também os adquiridos de terceiros, devem ser excluídos da base de cálculo do ISS não encontra respaldo no ordenamento jurídico, pois a regra legal que trata da incidência do ISS sobre serviços de construção civil é clara ao excluir apenas os materiais produzidos pelo próprio prestador fora do local onde prestados os serviços. 4. A situação do prestador que fabrica seus produtos fora do canteiro de obras não pode ser equiparada à daquele que adquire materiais de terceiros para uso nas obras de construção civil. Os produtos fabricados pelo prestador estão sujeitos ao ICMS, razão por que não devem se sujeitar a uma nova incidência de ISS. Já os produtos adquiridos de terceiros, se não incluídos na base de cálculo do ISS pelo serviço de construção civil, ficariam imunes à tributação, somente sendo tributados na operação anterior, que não tem o construtor como contribuinte ou responsável tributário. 5. Assim, quando os materiais são produzidos pelo próprio prestador fora do local onde prestados os serviços, incide ICMS; quando os materiais são produzidos pelo prestador no canteiro de obras ou quando são adquiridos de terceiros, como não há possibilidade de incidência de ICMS, devem ter seus valores mantidos na base de cálculo do ISS (STJ - AgRg no REsp 1002693/RS - Ministro CASTRO MEIRA - Data do Julgamento - 25/03/2008 - Data da Publicação/Fonte DJ 07.04.2008 p. 1).

18. VELLOSO, Andrei Pitten. Constituição Tributária Comentada. São Paulo: Atlas, 2007, p. 311.

19. Cf.DERZI, Misabel Abreu Machado, e COELHO, Sacha Calmon Navarro. Direito tributário aplicado: estudos e pareceres. Capítulos I e IV. Belo Horizonte, Del Rey, 1997, p. 34.

20. Cf. BARRETO, Aires F. Curso de Direito Tributário Municipal. ..., p. 410/412.

21. Cf. MELO, José Eduardo Soares de. Aspectos teóricos e práticos do ISS. São Paulo: Dialética, 2000 , p. 60.

22. TEODORO JR., Humberto. Curso de Direito Processual Civil. v. 01. Rio de Janeiro: Forense, 2007, p. 578.

23. APELAÇÃO CÍVEL Ação Declaratória c/c repetição de indébito - ISS - Serviços de construção civil e sub-empreiteira- Base de cálculo - Pretendida dedução dos materiais fornecidos - Possibilidade Matéria de Repercussão geral Jurisprudência do STF que reconhece a possibilidade de dedução da base de cálculo do ISS dos materiais empregados na construção civil. Sentença reformada - Recurso provido. (TJ-SP - 9105098-06.2009.8.26.0000 Apelação - Rel. Eutálio Porto - Data do julgamento: 27/10/2011 Órgão julgador: $15^{\mathrm{a}}$ Câmara de Direito Público).

24. DIREITO TRIBUTÁRIO. ISSQN. MANDADO DE SEGURANÇA. AUTORIZAÇÃO PARA ABATIMENTO, NA BASE DO CÁLCULO, DO ISSQN DECORRENTE DOS MATERIAIS UTILIZADOS NA CONSTRUÇÃO CIVIL. MATÉRIA COM REPERCUSSÃO GERAL. JURISPRUDÊNCIA DO STF ADMITINDO O ABATIMENTO DOS MATERIAIS ADQUIRIDOS DE TERCEIROS OU PRODUZIDOS FORA DO LOCAL DA OBRA. 1. A decisão, lastreada em acórdão do STF, que se sujeita ao regime do artigo $543-B$, $\S^{\circ}$, do CPC, ao reconhecer a possibilidade de dedução da base de cálculo do ISS dos materiais empregados na construção civil, não se submete a reforma pretendida, como, aliás, assim vem se posicionando a jurisprudência deste Tribunal de Justiça. 2. Decisão correta, na forma e no conteúdo, que integralmente se mantém. (TJ-RJ - 0005155-27.2011.8.19.0023 - apelação - Des. Maldonado de Carvalho - Julgamento: 22/05/2012 - Primeira Camara Civel).

25. TRIBUTÁRIO. IMPOSTO SOBRE SERVIÇOS - ISS. DEFINIÇÃO DABASE DE CÁLCULO. DEDUÇÃO DOS GASTOS COM MATERIAIS EMPREGADOS NA CONSTRUÇÃO CIVIL. POSSIBILIDADE. (TJPR $2^{\text {a }}$ C.Cível - ACR 894720-6 - Colorado - Rel.: Eugenio Achille Grandinetti - Unânime - J. 22.05.2012).

\section{REFERÊNCIAS}

AMARO, Luciano. Direito Tributário Brasileiro. 5. ed. São Paulo: Saraiva, 2000. 
ATALIBA, Geraldo; BARRETO, Aires F. ISS - Construção civil - Pseudo-serviço e prestação de serviço — Estabelecimento prestador - Local da prestação. Revista de Direito Tributário, n. 40, abr./jun. 1987.

ATALIBA, Geraldo. ISS - Base Imponível - Estudos e Pareceres de Direito Tributário. São Paulo: Revista dos Tribunais, 1974, v. 1.

BAPTISTA, Marcelo Caron. A norma tributária do Imposto sobre Serviços - ISS ênfase no consequente normativo. In: SANTI, Eurico Diniz de. Curso de Direito Tributário e Finanças Públicas. São Paulo: Saraiva, 2008.

BALEEIRO, Aliomar. Direito Tributário Brasileiro. Atualização por Mizabel Abreu Machadi Derzi. 11. ed. Rio de Janeiro: Forense, 2000.

BALEEIRO, Aliomar. Limitações Constitucionais ao Poder de Tributar. Atualização por Mizabel Abreu Machadi Derzi. 7. ed., Rio de Janeiro: Forense, 1998.

BARRETO FILHO, Oscar. Teoria do Estabelecimento Comercial. 1. ed. São Paulo: Max Limonad, 1969.

BARRETO. Paulo Ayres. O Adequado Tratamento Tributário do Ato Cooperativo, nos termos do Art. 146, III, "C", da CF", Tributação das Sociedades Cooperativas: XVI - Congresso Brasileiro de Direito Tributário - Instituto Geraldo Ataliba - IDEPE - Instituto Internacional de Direito Público e Empresarial. Revista de Direito Tributário - 87, São Paulo: Malheiros Editores, 2002.

BARRETO, Aires F. Curso de Direito Tributário Municipal. São Paulo: Saraiva, 2009, p. 322.

BARRETO, Aires F. O ISS na Constituição e na Lei. São Paulo: Dialética, 2003, p. 345.

BARROSO, Luís Roberto. Interpretação e Aplicação da Constituição. São Paulo: Saraiva, 2004.

BORGES, Jose Souto Maior. Aspectos fundamentais da competência municipal para instituiro ISS. (do decreto-lei 406/68 à LC n. 116/2003). In: TORRES, Heleno Taveira (Org.). Imposto sobre serviços - ISS na lei complementar 116/2003 e na constituição. São Paulo: Manole, 2004, p. 3-51.

CANOTILHO, José Joaquim Gomes. Direito constitucional. Lisboa: Almedina, 2010.

CARRAZA, Roque Antonio. Curso de direito Constitucional Tributário. 3. ed. São Paulo: Malheiros, 2009 .

CARRAZA, Roque Antonio. A tributação na Constituição, o princípio da autonomia municipal e o imposto sobre serviços de qualquer natureza (ISS). Questões conexas. In: SANTI, Eurico Marcos Diniz de. Curso de Direito Tributário e Finanças Públicas. São Paulo: Saraiva, 2008.

CARVALHO, Paulo de Barros. Curso de Direito Tributário. São Paulo: Saraiva, 2011.

CARVALHO, Paulo de Barros. Direito Tributário - Fundamentos Jurídicos da Incidência. 2. ed., revista. São Paulo: Saraiva, 1999.

DERZI, Misabel Abreu Machado; COELHO, Sacha Calmon Navarro. Direito tributário aplicado: estudos e pareceres. Capítulos I e IV. Belo Horizonte, Del Rey, 1997. 
DINIZ, Maria Helena. Curso de direito civil brasileiro. v. 2. São Paulo: Saraiva, 2002.

GONCALVES, Gilberto Rodrigues. ISS na construção civil. São Paulo: RBB, 1998.

HARADA, Kiyoshi. Direito Financeiro e Tributário. São Paulo: Atlas, 2004

JUSTEN FILHO, Marçal. O Imposto Sobre Serviço na Constituição. São Paulo: Revista dos Tribunais, 1985.

MACHADO, Hugo de Brito. Curso de Direito Tributário. 17. ed. São Paulo: Malheiros, 2000.

MACHADO, Hugo de Brito. O conceito de serviço e algumas modalidades listada no anexo da LC n. 116/2003. In: TORRES, Heleno Taveira (Org.). Imposto sobre serviços - ISS na lei complementar 116/2003 e na constituição. São Paulo: Manole, 2004, cap. 23, p. 559-578.

MELLO, José Eduardo Soares de. Aspectos teóricos e práticos do ISS. 2. ed. São Paulo: Dialética, 2000 .

MERELLES, Hely Lopes. Direito Municipal Brasileiro. São Paulo: Malheiros, 1993.

PEIXOTO, Marcelo Magalhães; CARDOSO, Laís Vieira. Comentários à lista de serviços anexa a lei complementar 116/03. In: MARTINS, Ives Gandra da Silva; PEIXOTO, Marcelo Magalhães (Org.). ISS lei complementar 116/2003. Curitiba: Juruá, 2008, p. 369-426.

TEODORO JR., Humberto. Curso de Direito Processual Civil. v. 01. Rio de Janeiro: Forense, 2007.

TORRES, Ricardo Lobo. Curso de Direito Financeiro e Tributário. 9. ed. Rio de Janeiro: Renovar, 2002.

VELlOSO, Andrei Pitten. Constituição Tributária Comentada. São Paulo: Atlas, 2007.

Recebido em: 07/04/2019

Aceito em: 10/09/2019 